\title{
Response to Gordon 2016
}

\section{Richard Lee $\mathbb{}^{\circledR}$, Drew Van Orden, Matt Sanchez}

RJ Lee Group, Inc., Monroeville, PA, USA

Dear Editor,

We appreciate the opportunity to respond to Dr. Gordon's comments ${ }^{1}$ on our Letter to the Editor ${ }^{2}$ concerning the weaknesses in his original paper, "Asbestos in commercial cosmetic talcum powder as a cause of mesothelioma in women.”3 Dr. Gordon has misquoted his own publications and he incorrectly claims we did not identify grunerite asbestos (amosite) in a sample of lung tissue.

Gordon, Fitzgerald, and Millette (GFM) incorrectly claimed that prior work had established a link between asbestos contaminated talc and ovarian cancer. Our objection to the original paper and to the Dr. Gordon rebuttal ${ }^{1}$ is that the scientific literature does not support a link between ovarian cancer and talc contaminated with anthophyllite asbestos as claimed by the authors. GFM (page 318, paragraph 1) state, "Previous research suggests that ovarian cancer and peritoneal mesothelioma may be directly attributed to the use of talcum powder contaminated with asbestos or from exposure to partners occupationally exposed to asbestos." GFM then cite three papers by Heller, ${ }^{46}$ of which Dr. Gordon was a co-author, and presumably was also the analyst who performed the work on which the papers were based in support of this statement. Yet, this previous research draws no such conclusions, and the implication of talc in ovarian cancer was not the point of the papers. The Heller papers documented the occurrence of asbestos in the ovaries and fallopian tubes of women who had known exposures to commercial asbestos compared to those who did not.

In reference 3 of $\mathrm{GFM}^{4}$, Heller et al. concluded "We have demonstrated that asbestos can reach the ovary and may be present even without known exposure." Heller also noted "None of the women had ovarian carcinoma. Some had a history of talc usage." The types of asbestos observed by Heller included chrysotile, crocidolite, and amosite; no anthophyllite asbestos was reported in the 21 women studied, even though some of the women were noted as having used perineal talcum powder. Heller went further, however, and excluded talcum powder as a

Correspondence to: Richard Lee, RJ Lee Group, Inc., Monroeville, PA, USA. Email: rlee@rilg.com potential source of asbestos: "Some older talc preparations contained asbestos, but this is no longer a concern. Some of the subjects did use perineal talc, but talc and asbestos are easily distinguished by electron microscopy, so our findings truly represent asbestos."

Reference 4 of GFM, ${ }^{5}$ Heller et al. clearly compare populations of women with and without exposure to commercial asbestos: "Ovaries were studied from 13 women with household contact with men with documented asbestos exposure and from 17 women undergoing incidental oophorectomy." Heller noted "Except for one case, in which tremolite was observed, the fibers were either chrysotile or crocidolite, or both." No mention was made of anthophyllite asbestos - the vast majority of the fibers reported by GFM - even though "In addition, talc was detected in 11/13 exposed women (85\%) and in all 17 controls $(100 \%)$. No asbestos or talc was detected in the stillborn material."

There is more to be gleaned from reference 4 of GFM. Table 3, reproduced below, which shows the type and size of asbestos fibers found in the ovaries of thirty women as reported by Heller et al. According to Table 3, 78 of 80 fibers $(97.5 \%)$ found in the ovaries had widths less than $0.2 \mu \mathrm{m}$, completely consistent with historical analysis of commercial asbestos in tissue. In contrast, of the fibers reported by GFM, $90 \%$ had diameters between 0.2 and $0.5 \mu \mathrm{m}$, representing a completely different population:

There are significant limitations to these methods. PLM analysis misses small fine asbestos fibers or fibrils because the limits of the resolution are approximately $0.2-0.5 \mu \mathrm{m}$ for different forms of light microscopy. Based on our findings, approximately $90 \%$ of the fibers identified fall into this category.

In reference 5 of GFM, ${ }^{6}$ Heller et al. specifically targeted the relationship between talc usage and talc content of the ovaries. In a study of 24 women, 12 of whom had no known talc exposure, they reported,

Talc as a possible etiologic agent in the development of epithelial ovarian cancer may be related to asbestos exposure in several ways. Aside from the chemical similarities between the two, many cosmetic talcs 
Table 3 Asbestos fibers in ovarian tissues: type, number, and dimensions

\begin{tabular}{|c|c|c|c|c|c|c|c|c|}
\hline Subject & No. of fibers & Fiber type & $<3 \mu \mathrm{m}$ long & $\begin{array}{l}\text { 3-10 } \mu \mathrm{m} \\
\text { long }\end{array}$ & $>10 \mu \mathrm{m}$ long & $\begin{array}{l}<0.1-\mu \mathrm{m} \\
\text { diameter }\end{array}$ & $\begin{array}{c}0.1-0.2-\mu \mathrm{m} \\
\text { diameter }\end{array}$ & $\begin{array}{l}>0.2-\mu \mathrm{m} \\
\text { diameter }\end{array}$ \\
\hline \multirow[t]{2}{*}{$1^{a}$} & 4 & Chrysotile & 1 & 2 & 1 & 4 & - & - \\
\hline & 8 & Crocidolite & 1 & 7 & - & 4 & 4 & - \\
\hline \multirow[t]{2}{*}{$3^{\mathrm{a}}$} & 40 & Chrysotile & 2 & 28 & 10 & 35 & 5 & - \\
\hline & 40 & Crocidolite & 3 & 31 & 6 & 30 & 10 & - \\
\hline $4^{a}$ & 4 & Chrysotile & - & 3 & 1 & 4 & - & - \\
\hline $5^{a}$ & 8 & Chrysotile & 1 & 6 & 1 & 7 & 1 & - \\
\hline $6^{a}$ & 80 & Chrysotile & 5 & 62 & 13 & 71 & 9 & - \\
\hline \multirow[t]{2}{*}{$8^{a}$} & 32 & Chrysotile & 2 & 22 & 8 & 22 & 10 & - \\
\hline & 8 & Tremolite & 1 & 7 & - & - & 6 & 2 \\
\hline \multirow[t]{2}{*}{$9^{a}$} & 1 & Chrysotile & - & 1 & - & 1 & - & - \\
\hline & 1 & Crocidolite & - & 1 & - & 1 & - & - \\
\hline $11^{\mathrm{a}}$ & 12 & Chrysotile & 1 & 9 & 2 & 8 & 4 & - \\
\hline $12^{\mathrm{a}}$ & 20 & Crocidolite & 2 & 14 & 4 & 12 & 8 & - \\
\hline \multirow[t]{2}{*}{$1^{b}$} & 10 & Chrysotile & 1 & 8 & 1 & 4 & 6 & - \\
\hline & 20 & Crocidolite & 2 & 18 & - & 17 & 3 & - \\
\hline \multirow[t]{2}{*}{$2^{b}$} & 8 & Chrysotile & - & 7 & 1 & 5 & 3 & - \\
\hline & 8 & Crocidolite & 1 & 7 & - & 6 & 2 & - \\
\hline $3^{b}$ & 4 & Chrysotile & - & 4 & - & 3 & 1 & - \\
\hline \multirow[t]{2}{*}{$4^{b}$} & 4 & Chrysotile & - & 4 & - & 3 & 1 & - \\
\hline & 8 & Crocidolite & 1 & 7 & - & 7 & 1 & - \\
\hline $5^{b}$ & 8 & Crocidolite & - & 8 & - & 6 & 2 & - \\
\hline $6^{b}$ & 80 & Chrysotile & 7 & 58 & 15 & 68 & 12 & - \\
\hline
\end{tabular}

aFrom Table 1.

'From Table 2.

Reproduced from Ref. [5]

contained significant amounts of asbestos, particularly before 1976. Although tremolite asbestos has been documented as a containment of some talc preparations, the types of asbestos detected here are more commonly associated with an environmental (chrysotile) or occupational (chrysotile and crocidolite) exposure. The detection of talc in all the ovaries demonstrates that talc can reach the upper genital tract. However, the quantity detected in this study did not correlate well with the reported exposure. Further study is required to elucidate whether the presence of talc in ovarian tissue is pathogenic.

Again, no anthophyllite asbestos was reported in any sample included in this study.

Thus, in the studies claimed by Dr. Gordon to support his supposedly unbiased academic opinion, not one anthophyllite asbestos fiber was reported, even though in the GFM paper,

Initial bulk analyses of 50 samples of this product in Laboratory A showed that all of the samples contained asbestos fibers. Eighty percent contained only anthophyllite asbestos, $8 \%$ only tremolite asbestos, $8 \%$ anthophyllite and tremolite asbestos and 4\% anthophyllite, tremolite, and chrysotile.

According to Dr. Gordon, anthophyllite asbestos was found in $92 \%$ of the bulk commercial cosmetic samples he examined. But that was not the case, not even once, in the ovarian cancer papers he cited..$^{4-6}$

Dr. Gordon's citations do not support the claim that talc contaminated with anthophyllite asbestos was associated with ovarian cancer. Instead, with one exception, only chrysotile, crocidolite and amosite were reported in the cited papers, all with diameters less than $0.2 \mu \mathrm{m}$. Moreover, these data raise serious questions about the credibility of the GFM authors, particularly Dr. Gordon. If in 50 samples of cosmetic talc, more than $80 \%$ contained anthophyllite asbestos, how is it that no anthophyllite asbestos made it into the ovaries of the women in his prior body of work?

There is a larger deception in not identifying the fact that this is a completely novel finding. Dr. Gordon's citations describe the analysis of more than 70 samples from women's fallopian tubes or ovaries. These results were previously reported in peer-reviewed journals by Dr. Gordon as having had no anthophyllite asbestos - even though talc was found in some of the samples. By citing these analyses as support for the premise that prior research linked asbestos-contaminated talc with ovarian cancer, Dr. Gordon misled the reviewers and the readers into thinking his results were supported by prior science. Instead the prior literature points to the fact that his current findings have no basis. This is an intolerable scientific misrepresentation. Dr. Gordon's own analysis of some 70 ovaries and fallopian tube samples found only evidence of commercial asbestos exposure, not the anthophyllite asbestos he claimed to have been found in every analysis of some 50 samples.

Dr. Gordon incorrectly claims that RJ Lee Group (RJLG) misidentified anthophyllite asbestos in lung tissue as amosite. Dr. Gordon states,

These chemical variances and inconsistencies in the mineral fraction isolated from the lung tissue of the woman at issue in this case were therefore clear indicators that the dominant asbestos type in the tissue was anthophyllite, wrongly identified by the laboratory of the author of the letter to the editor as amosite. ${ }^{1}$

Dr. Gordon based his argument that the particles were anthophyllite on the ratios of iron to silica in several particles not matching those expected for amosite. Dr. Gordon 

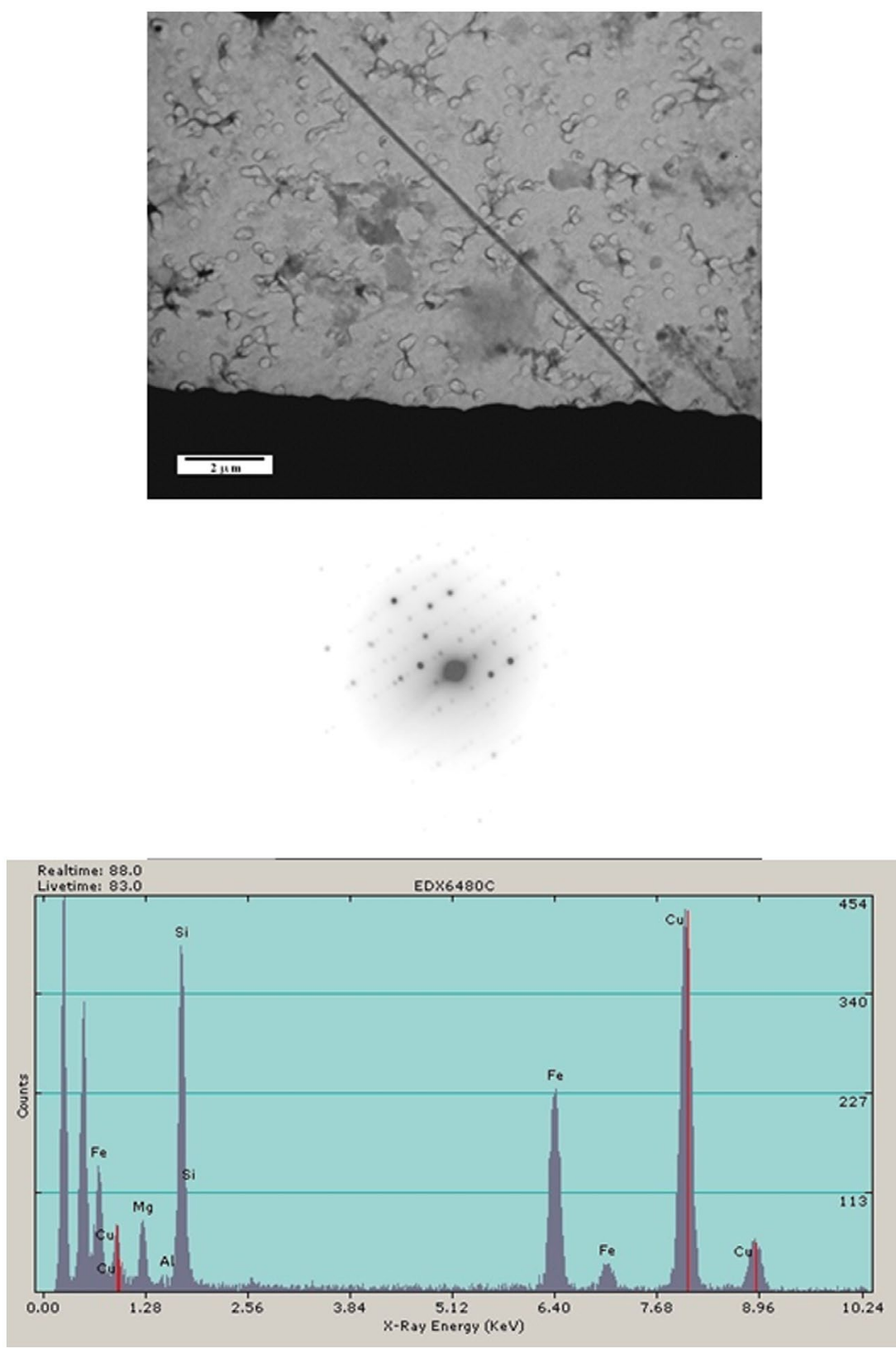

Figure 1 Photograph (top), selected area electron diffraction pattern (middle), and energy-dispersive X-ray spectrum (bottom) for an uncoated amosite fiber observed in the particulate from the lung tissue of a woman.
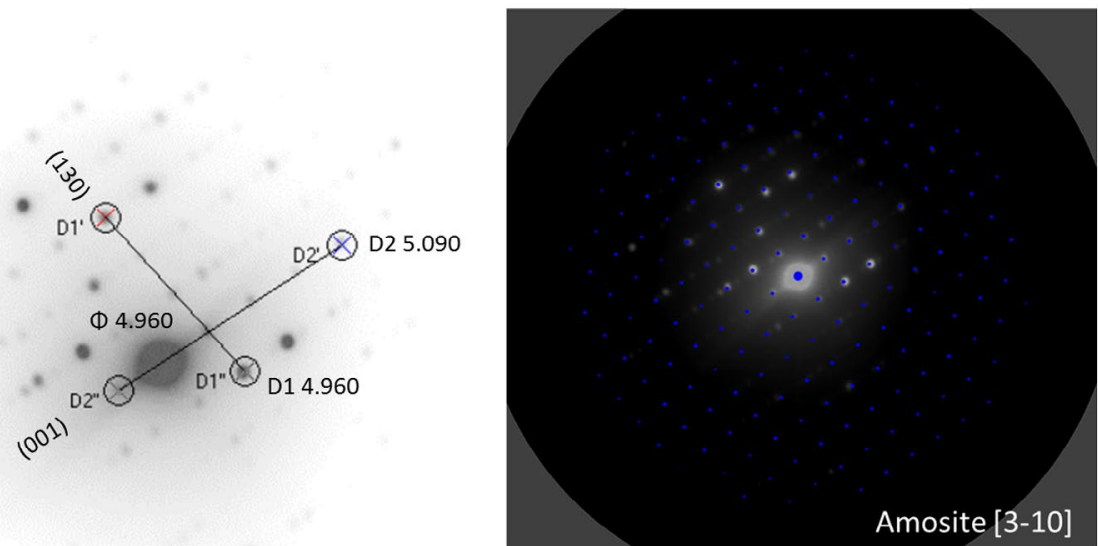

Figure 2 The Selected Area Electron Diffraction (SAED) is presented in two forms: left is the digitized pattern with the d-spacing and angle used to search for potential solutions and right has the pattern overlaid with the simulated solution derived by the search routine.

Note: The indexed SAED is a classic [310] monoclinic diffraction pattern, not an orthorhombic pattern. 
missed the fact that in all cases of uncoated fibers, the magnesium $(\mathrm{Mg})$ peak was smaller than the iron $(\mathrm{Fe})$ peak, making the particles inconsistent with anthophyllite. Dr. Gordon showed his bias by ignoring the fact that in the same TEM grids in which he claims particles were misidentified, RJLG located 21 amosite particles which were not coated, and for which conclusive data to identify them as amosite was obtained (see figure below). In Figure 1, we show the morphology of a particle which is consistent with amosite asbestos.

The energy-dispersive X-ray spectroscopy spectra are consistent with an iron amphibole. The Selected Area Electron Diffraction pattern (SAED) is presented in two forms: Figure 2 (left) is the digitized pattern with the $\mathrm{d}$-spacing and angle used to search for potential solutions, and Figure 2 (right) has the pattern overlaid with the simulated solution derived by the search routine.

The indexed SAED is a classic [310] monoclinic diffraction pattern, not an orthorhombic pattern, as would be the case if the particles were anthophyllite asbestos. Dr. Gordon exhibits bias and lack of academic integrity by claiming that he had simple, clean identification of a unique exposure when it is clear that the patient had multiple sources of exposure.

Dr. Gordon misrepresented the scientific literature, which he claimed demonstrated the presence of asbestos in historical talc. GFM, ${ }^{3}$ citing Rohl and Langer ${ }^{7}$ stated,

In 1976, Rohl and Langer tested 20 consumer products labeled as talc or talcum powder, including body powders, baby powders, facial talcums, and a pharmaceutical talc. Of the 20 products tested, 10 were found to contain tremolite and anthophyllite, principally asbestiform. The product with the highest asbestos content was the same product tested in this study. Both asbestiform anthophyllite and asbestiform tremolite were found in the Rohl and Langer tests. Given that asbestos has been determined as the primary cause of mesothelioma, it is important to note that cosmetic talc contained asbestos in the past.

However, in Appendix A of the Rohl and Langer article, ${ }^{7}$ it is clearly stated that "we do not refer to anthophyllite and tremolite fibers in these talcums as asbestos. Instead they are referred to as asbestiform." Langer reiterated this recently in a communication to Drew Van Orden. ${ }^{8}$ Langer states

The appendices explain the nomenclature we used. We did not state that asbestos was present in consumer talcum but that on the TEM scale we could not distinguish between cleavage fragment and amphibole asbestos fibril when finding a single isolated particle. If we didn't know the nature of the source materials we could not (at that time) distinguish between the forms. We even had a paragraph or two in the talc paper with some attribution to grunerite and amosite. We were deep into the blue mists of Lake Superior.
Thus, Rohl et al. clearly understood they were not looking at asbestos, yet Dr. Gordon uses their work to conclude that cosmetic talc contained asbestos in the past. This is unethical and clearly framed to support his litigation argument.

Similar problems are found in the references cited to support the premise that anthophyllite asbestos was found in the talc mines that supplied the talc to the cosmetic talc producer. None of these references report asbestos, let alone anthophyllite asbestos, in the talc ores in question as we pointed out in our original letter. ${ }^{2}$

Dr. Gordon's paper ${ }^{3}$ and his Letter to the Editor ${ }^{1}$ contain two types of errors. The first, improper citations could be deemed as simply sloppy work, but because it happened repeatedly throughout his paper and was repeated in his Letter, we believe it demonstrates bias and lack of integrity. The second, the causal issues leading to the three laboratories misidentifying particles in talc as anthophyllite is a complex technical issue. The root problem is that Dr. Gordon, while very experienced in tissue analysis for commercial asbestos, was completely inexperienced in the analysis of talc and has no knowledge of mineralogy. ${ }^{9,10}$

Had Dr. Gordon understood talc mineralogy, he would have known that talc deposits contain fibers which are intergrowths between amphibole and talc as well as talc fibers that are highly asbestiform. However, as pointed out by Crane of the Occupational Safety and Health Administration, these are not anthophyllite asbestos even though they produce SAED patterns that cannot be visually separated from those of amphiboles. Crane says

when viewed in the TEM, almost all of the fibers appear to be anthophyllite using the usual techniques of asbestos analysis applied to the asbestos abatement industry. The diffraction patterns are sufficiently similar that using only pattern recognition, a mistake is made. [...] The cure, in this case, is careful analysis. Pattern recognition for SAED contains a number of pitfalls which should be avoided by indexing whenever practical. Whenever general mineralogical materials might be present beyond the commercial asbestos minerals, it is very important to step beyond the short set of identification criteria and fully identify the fibers present. ${ }^{11}$

Crane's memo points out the difficulty of separating these intermediate fibers in talc from amphibole asbestos. Failure to address this issue is what led to the mistakes by Dr. Gordon in the original paper. ${ }^{3}$ The problem is not confined to Dr. Gordon and his comrades. There are currently many laboratories that have been performing routine asbestos analysis for years and that are now starting to analyze samples for naturally occurring asbestos; they will find themselves in the same boat if they do not recognize and understand the complexity of the mineralogy of the system they are studying. Failure to follow appropriate analytical methods completely will continue to lead to findings of asbestos where none exists at great expense to industry and to our health professionals as they strive to understand reality. 


\section{Disclosure statement}

No potential conflict of interest was reported by the authors.

\section{ORCID}

Richard Lee (D) http://orcid.org/0000-0003-1974-2066

\section{References}

1 Gordon RE. Response to RE: Gordon R, Fitzgerald S, and Millette $\mathrm{J}$. Asbestos in commercial cosmetic talcum powder as a cause of mesothelioma in women. Int J Occup Environ Health. 2014;20(4):31832. Int J Occup Environ Health. 2015;21(4):342-6.

2 Lee RJ, Van Orden DR. Letter to the Editor RE: Asbestos in commercial talcum powder as a cause of mesothelioma in women. Int J Occup Environ Health. 2014;20(4):318-332. Int J Occup Environ Health. 2015;21(4):337-41.

3 Gordon R, Fitzgerald S, Millette J. Asbestos in commercial cosmetic talcum powder as a cause of mesothelioma in women. Int J Occup Environ Health. 2015;20(4):318-32.
4 Heller DS, Gordon RE, Katz N. Correlation of asbestos fiber burdens in fallopian tubes and ovarian tissue. Am J Obstet Gynecol. 1999;181(2):346-7.

5 Heller DS, Gordon RE, Westhoff C, Gerber S. Asbestos exposure and ovarian asbestos fiber burden. Am J Ind Med. 1996;29(5) 435-9.

6 Heller DS, Westhoff C, Gordon RE, Katz N. The relationship between perineal cosmetic talc usage and ovarian talc particle burden. Am J Obstet Gynecol. 1996;174(5):1507-10.

7 Rohl AN, Langer AM, Selikoff IJ, Tordini A, Klimentidis R, Bowes DR, Skinner DL. Consumer talcums and powders: mineral and chemical characterization. J Toxicol Environ Health A. 1976;2(2):255-84.

8 Langer A. E-mail correspondence to Drew Van Orden Re: Sean Fitzgerald. Jan 30, 2014.

9 Deposition of Ronald E. Gordon, Ph.D. June 14, 2011. Bernard v. Brookfield Properties Corp., et al., p. 113:25-115:16.

10 Videotaped Deposition of Ronald E. Gordon, Ph.D. Mar 20, 2015. Judith and John Winkel v. Calaveras Asbestos, Ltd., et al., at 64:1-8, 65:19-21, 133:17-135:16, 136:3-17.

11 Crane DT. Background information regarding the analysis of industrial talcs. Salt Lake City (UT): OSHA; 2000. 